\title{
Editorial:
}

\section{Themes on the Meaning of Professionalism and Setting New Directions for Policy and Practice}

\author{
Dolana Mogadime \\ Editor \\ Brock University
}

I welcome the work of being the new Editor of Brock Education Journal. The related tasks situate me in a position where I can: support colleagues and the larger academic community; as well as carry forward the vision and scholarly reputation of the journal. I have the absolute pleasure of gaining knowledge, appreciation and value for the intellectual work for which my colleagues endeavor and labour. The fruits of which may be fully enjoyed by our readers. As a research journal of many years, Brock Education has been a source of insight and I look forward to continuing this tradition and to moving it in new directions that represent the current educational landscape.

The articles featured in this issue take up notions of professionalism as it occurs across a broad range of educational terrains. Multiple educational theories and research approaches are employed to strengthen and support professionalism across the continuum from pre-service and in-service teacher education to school leadership. Reading across these articles, students' and educators' points of views are envisioned that push for a meaningful appreciation of learning and for changes in the ways that facilitate envisioning learning more broadly.

Many of the articles share a commitment to empirical studies as they each carefully report on the ongoing research projects that faculty members, teachers in schools and students have both forged and participated in. They invite us in to learn about the commitment to professional learning that takes place through collaborative university-school partnerships and research endeavors from national and international contexts. Moreover, readers stand to gain valuable knowledge from conceptually based research inquiry that details in-depth analysis of policy and then further provides insights into understanding the policy to practice gaps.

\section{Research themes concerned with professionalism}

Maynes and Hatt's article, 'Conceptualizing How Mature Teachers Can influence Students' Growth in Learning' is based on their research study with faculty advisors who work with preservice teachers. Within their capacity as advisors they take on multiple roles as instructors, mentors/evaluators of pre-service teachers. The authors' central question is: "Do mature teachers have a stronger focus on student learning than less mature teachers?" By documenting the elements of mature teachers' practice that focuses on 'student learning' rather than on 'teaching' Maynes and Hatt's work assists teacher educators and professional developers to access 
knowledge about 'consciously competent professionals' who have undergone a profound shift that increases optimal student learning.

Chow, Chu, Tavares and Lee's article investigates the role of teacher-research on inservice teachers' professional development in Hong Kong. Teachers from four primary schools participated in focus group interviews about a "school-university collaborative research project that promotes collaborative inquiry project-based learning (inquiry PJBL)". The authors delineate the impact of teacher-research on professionalism by examining four dimensions: knowledge enrichment, school culture, teaching practice and curriculum design. The findings are quite instructive for international audiences. Of interest is evidence about the benefits of teacher research that directly result from university-school collaboration.

Knouzi and Mady's article takes on a twofold approach in its reach into supporting professional knowledge for both pre-service and in-service teachers. Their work "describes a study of an online learning environment that sought to increase L2 teachers'/teacher candidates (T/TCs) access to research and to enhance communication between L2 T/TC and researchers by providing a mutual space for such interaction." The authors created a virtual space to facilitate communication between the otherwise desperate groups and in doing so redressed "one of the causes of the linkage gap identified in the literature, namely the lack of a shared space." This kind of work paves the way to new conceptualizations for the future landscape of education.

Pinto and Foulkes' article report on an ongoing innovative school-based research project that examines the impact of a vocationally-oriented cooperative program on students' well-being. Their study “draws on Martha Nussbaum's (2000) account of the nature of human well-being in order to explore the role of animals in formal education settings." Pinto and Foulkes incorporate a research design that places students' voices at the centre to arrive at an understanding about positive effects of animals in educational settings. Their study sheds a light on a largely underexplored area - the potential social and health benefits of dog-human interaction.

\section{Research themes concerned with policy and leadership}

Gray's article is based on a study that examines, "eating behaviours and nutrition knowledge of young women in an Ontario secondary school." Twenty semi-structured interviews with female students between the ages of $14-17$ provide insight into how young women negotiate and resist nutrition messages they receive within the school environment that can be in conflict with Ontario Ministry of Education nutrition policy. Gray queries about the impact school environments and parental influence has on adolescents' knowledge about nutrition.

Karrow and Fazio's policy analysis article is organized into two sections, the first of which "provides a curricular critique of an environmental policy framework called Acting Today, Shaping Tomorrow" (2009). Answers to the following two curricular questions: "What should be taught?" and "How it should be taught?" frame the critique." The second section, engages with the limitations of using a typology of integrated curriculum referred to as 'selective infusion.' Karrow and Fazio's work goes beyond a critique to advance a set of "recommendations for improving the policy framework from a pragmatic curricular perspective." The balance the authors attain between critique and setting new directions are as informative as they are instructive. 
Armstrong's article pushes the boundaries as it examines transitions professionals undergo from teaching to administration. By utilizing a qualitative research approach that is informed by the voices of vice-principals, she identifies the following obstacles they undergo, "ambiguous legal and institutional configuration of the vice-principalship, inadequate preparation for challenging front line managerial and disciplinary roles and inappropriate transition support." Armstrong's research results surmise that substantive change needs to occur during these transitions and that concerted coordinated efforts to bring about change are required by "school districts, policy makers, professional associations and regulatory bodies." Armstrong argues that supportive coordinated efforts for the transition from teaching to administration stand to better support leadership challenges facing schools today.

This issue brings together research that both contributes to the conversation on professionalism and sets a new pace for thinking through its extended meaning in relation to teachers, educators and aspiring school leaders. Furthermore, the work featured in the journal provokes debate about the capacity and vision for research to become a harbinger for positive change. 